\title{
Reversal of doxorubicin-resistance by Salvia miltiorrhiza ligustrazine in the SHG44/doxorubicin glioma drug-resistant cell line
}

\author{
FENG WANG, NING HUANG, QIANG YANG, JUN LIU and JIN CHEN
}

Department of Neurosurgery, The Second Affiliated Hospital of Chongqing Medical University, Chongqing 400010, P.R. China

Received January 11, 2016; Accepted June 2, 2017

DOI: 10.3892/ol.2017.6775

\begin{abstract}
The multidrug resistance of glioma impedes chemo-radiotherapy and leads to adverse outcomes. In the present study, the doxorubicin (DOX)-resistant glioma SHG44/DOX cell line was established to investigate the effects and mechanisms of Salvia miltiorrhiza ligustrazine (SML), a traditional Chinese medicine, on the reversal of DOX-resistance. The SHG44/DOX cells grew continually in $0.1 \mu \mathrm{g} / \mathrm{ml}$ DOX and expressed increased levels of mRNA of multidrug resistance genes [multidrug resistance 1 (MDR1), multidrug resistance-associated protein 1 (MRP1) and lung resistance protein (LRP)] compared with the parental SHG44 cells. Treatment with DOX plus SML suppressed proliferation and promoted early apoptotic rates in SHG44/DOX cells, although treatment with DOX alone failed to inhibit SHG44/DOX cells. In addition, the levels of MDR1, MRP1 and LRP were downregulated by this traditional Chinese medicine, coupled with increased intracellular DOX concentrations. Tumor-bearing nude mouse models were also established using SHG44/DOX cells, and it was demonstrated that the tumor volumes and proliferation indexes were lower in the DOX plus SML group compared with the DOX alone group. The present data demonstrated that treatment with SML was able to reverse the DOX resistance of SHG44/DOX cells, which suggests that SML may be a potential adjuvant agent for glioma chemo-radiotherapy.
\end{abstract}

\section{Introduction}

Glioma is the most common type of malignant tumor in the central nervous system, and the annual incidence reaches $\sim 7.2 / 100,000$ (1). Owing to invasive growth and intraoperative protection of the functional areas of the brain, it is difficult to remove the tumor completely by surgery, and

Correspondence to: Dr Jin Chen, Department of Neurosurgery, The Second Affiliated Hospital of Chongqing Medical University, 74 Linjiang Road, Yuzhong, Chongqing 400010, P.R. China E-mail: dazushike@163.com

Key words: glioma, Salvia miltiorrhiza ligustrazine, doxorubicin, multidrug resistance, chemotherapy therefore postoperative chemo-radiotherapy becomes an important strategy for glioma (2). However, glioma cells are not sensitive to clinical radiotherapy and chemotherapy due to multidrug resistance, resulting in recurrence even if surgery and postoperative chemo-radiotherapy are combined, with a mean survival time of $<14$ months (3). Increasing evidence has indicated that high expression of ATP-binding cassette transporter is one of the important factors involved in tolerance to chemo-radiotherapy in glioma (4-6). Furthermore, drug-resistance of glioma cells may be abolished by decreasing the expression and function of the ATP-binding cassette transporter family members in the cell membranes (7). Therefore, this may be a potential clinical strategy for the treatment of glioma (8). In the present study, the traditional Chinese medicine Salvia miltiorrhiza ligustrazine (SML) was revealed to inhibit the expression of multidrug resistance 1 (MDR1), multidrug resistance-associated protein 1 (MRP1) and lung resistance protein (LRP) and promote the antitumor effect of doxorubicin (DOX) in the DOX-resistant glioma SHG44/DOX cell line. Data from the present study confirmed the novel function of this drug in tumor treatment. Therefore, SML may be a potential adjuvant agent for glioma chemo-radiotherapy.

\section{Materials and methods}

Reagents. Fetal bovine serum (FBS), RPMI-1640 medium and penicillin/streptomycin were purchased from HyClone (GE Healthcare Life Sciences, Logan, UT, USA). LRP, phosphorylated-glycoprotein (p-gp), MRP1, GAPDH, Ki-67 nuclear antigen and proliferating cell nuclear antigen (PCNA) primary antibodies were purchased from Santa Cruz Biotechnology, Inc. (Dallas, TX, USA). Horseradish peroxidase-conjugated secondary antibodies were purchased from OriGene Technologies, Inc. (Beijing, China). DOX and SML were obtained from the Department of Neurosurgery at The Second Affiliated Hospital of Chongqing Medical University (Chongqing, China).

Cell culture. The human glioma SHG44 cell line was purchased from Shanghai Life Academy of Sciences Cell Library (Shanghai, China). The SHG44 cells were maintained in RPMI-1640 supplemented with $100 \mathrm{U} / \mathrm{ml}$ penicillin, $100 \mathrm{mg} / \mathrm{ml}$ streptomycin and $10 \% \mathrm{FBS}$ at $37^{\circ} \mathrm{C}$. To establish the DOX-resistant SHG44 (SHG44/DOX) cell line, concentrations 

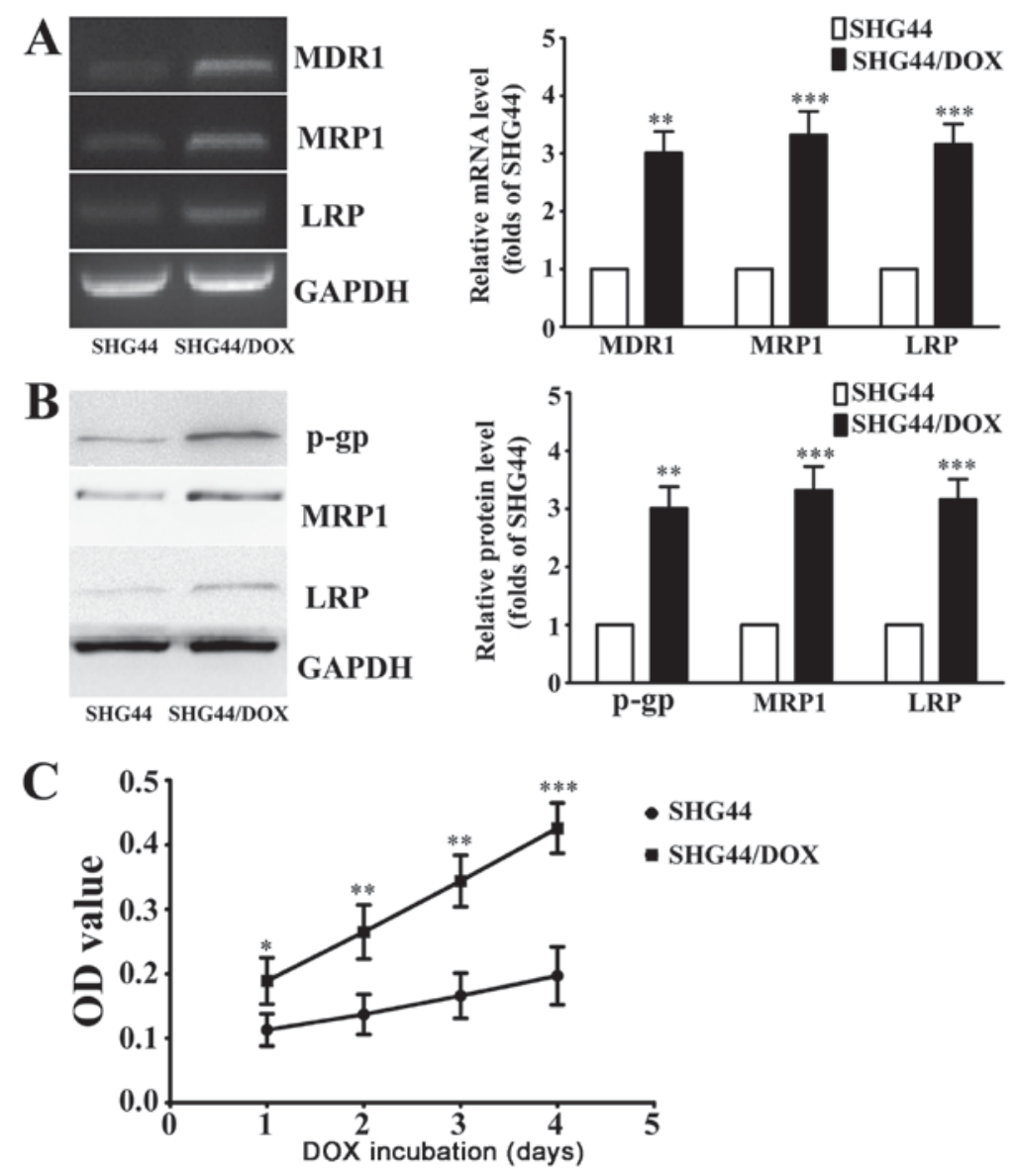

Figure 1. Characteristics of the DOX-resistant glioma SHG44/DOX cell line. (A) Reverse transcription-polymerase chain reaction analysis of mRNA levels of MDR1, MRP1 and LRP in SHG44 and SHG44/DOX cells (n=5). (B) Western blot analysis was used to determine the expression of three resistance proteins in SHG44 and SHG44/DOX cells $(\mathrm{n}=5)$. (C) Following incubation with $0.1 \mu \mathrm{g} / \mathrm{ml}$ DOX for 1, 2, 3, 4 days, cell viability was detected using cell counting kit-8 solution ( $\mathrm{n}=9)$. ${ }^{*} \mathrm{P}<0.05,{ }^{* *} \mathrm{P}<0.01,{ }^{* * * *} \mathrm{P}<0.001$ vs. SHG44 cells. DOX, doxorubicin; MDR1, multidrug resistance 1; MRP1, multidrug resistance-associated protein 1; LRP, lung resistance protein; p-gp, phosphorylated-glycoprotein; OD, optical density; SHG44/DOX, DOX-resistant SHG44 cell line.

of DOX treatment were increased gradually between 0.01 and $1 \mu \mathrm{g} / \mathrm{ml}$. Finally, the SHG44/DOX cells were able to grow continually in medium with $0.1 \mu \mathrm{g} / \mathrm{ml} \mathrm{DOX}$.

Semi-quantitative reverse transcription polymerase chain reaction $(R T-P C R)$. Total RNA was extracted from cells using RNAiso Plus (Invitrogen; Thermo Fisher Scientific, Inc., Waltham, MA, USA). The concentrations of these RNA samples were measured using a spectrophotometer, and the RNA samples were reverse-transcribed into cDNA using the Primescript RT reagent kit according to the manufacturer's protocol (Takara Biotechnology Co., Ltd., Dalian, China). The primer sequences and product sizes were as follows: LRP (221 bp) forward, 5'-GTCTTCGGGCCTGAGCTG GTGTCG-3' and reverse, 5'-CTTGGCCGTCTCTTGGGG GTCCTT-3'; MRP1 (326 bp) forward, 5'-CCGTGTACTCCA ACGCTGC-3' and reverse, 5'-CTGGACCGCTGACGCCGT GAC-3'; MDR1 (310 bp) forward, 5'-CATGCTCAGACAGGA TGTGAGT-3' and reverse, 5'-AGTAGCGATCTTCCCAGA ACCT-3' and GAPDH (598 bp) forward, 5'-CCACCCATG GCAAATTCCATGGCA-3' and reverse, 5'-TCTAGACGG CAGGTCAGGTCCAC-3'. The amplification conditions were as follows: $95^{\circ} \mathrm{C}$ for $5 \mathrm{~min}, 95^{\circ} \mathrm{C}$ for $30 \mathrm{sec}, 54.5^{\circ} \mathrm{C}$ for $30 \mathrm{sec}$ and $72^{\circ} \mathrm{C}$ for $40 \mathrm{sec}$. The PCR program was administered for
30 cycles, followed by a 5 min extension at $72^{\circ} \mathrm{C}$. The experiment was repeated five times. Following gel electrophoresis in $2 \%$ agarose gel, ethidium bromide was used to observe the bands using Quantity One 4.6 computer software at $590 \mathrm{~nm}$ (Bio-Rad Laboratories, Inc., Hercules, CA, USA). The relative levels of target genes were normalized to GAPDH expression.

Western blot analysis. The cells were lysed using radioimmunoprecipitation assay lysis buffer (Beyotime Institute of Biotechnology, Beijing, China) containing 1\% phenylmethylsulfonyl fluoride. The BCA method was used to determine protein concentrations. An equal amount $(25 \mu \mathrm{g})$ of each sample was separated by 6-10\% SDS-PAGE and transferred to polyvinylidene fluoride (PVDF) membranes. Following blocking with $5 \%$ goat serum at $37^{\circ} \mathrm{C}$ for $30 \mathrm{~min}$ (Beijing Zhongshan Golden Bridge Biotechnology Co., Ltd., Beijing China) and incubating with primary antibodies against $\mathrm{p}-\mathrm{gp}$ (dilution, 1:300; cat. no. sc71557), MRP1 (dilution, 1:300; cat. no. sc7773), LRP (dilution, 1:300; cat. no. sc135975) and GAPDH (dilution, 1:1,000; cat. no. sc47724) overnight at $4^{\circ} \mathrm{C}$, the PVDF membranes were washed three times with PBS and Tween-20 (PBST) buffer and incubated with horseradish peroxidase-conjugated goat anti-rabbit or anti-mouse secondary antibody (dilution, 1:5,000; cat. nos. TA130003 and 


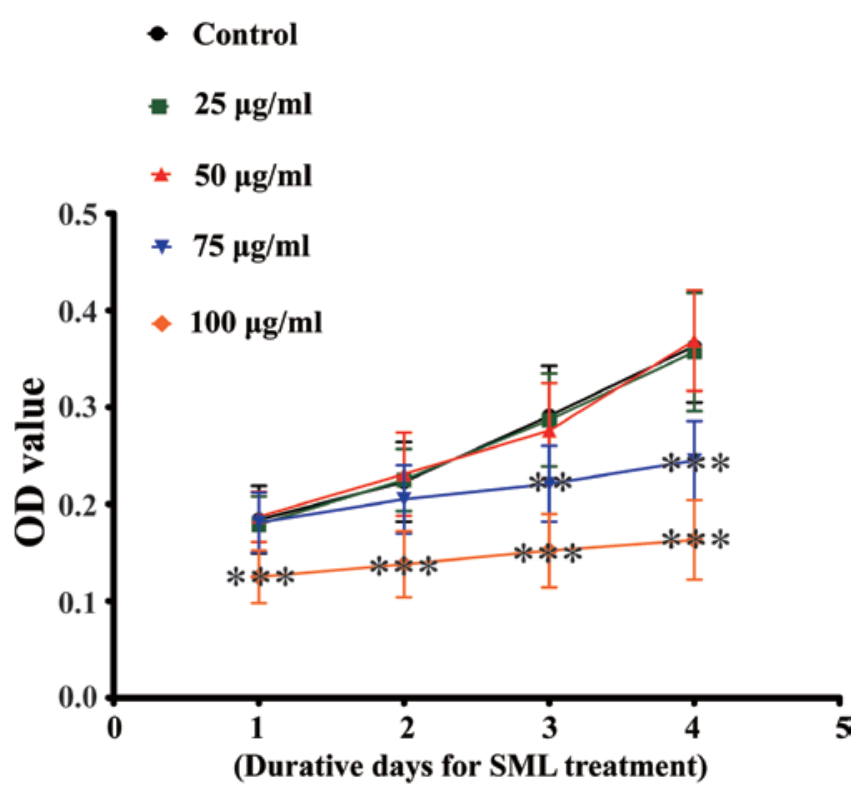

Figure 2. Viability of doxorubicin-resistant SHG44 cells was analyzed following persistent treatment with $25,50,75$ and $100 \mu \mathrm{g} / \mathrm{ml}$ Salvia miltiorrhiza ligustrazine for $1,2,3$ and 4 days $\left(\mathrm{n}=9 ;{ }^{*} \mathrm{P}<0.05,{ }^{* *} \mathrm{P}<0.01\right.$, ${ }^{* * *} \mathrm{P}<0.001$ vs. control at the same time point). OD, optical density.

TA130023) for $1 \mathrm{~h}$ at $37^{\circ} \mathrm{C}$. The membranes were then washed three times with PBST buffer and the amount of protein in each band was observed using enhanced chemiluminescence reagents (Beyotime Institute of Biotechnology) and quantified using Quantity One 4.6 computer software. GAPDH was used as a loading control. The experiment was repeated five times.

Cell viability. The cells were seeded onto 96-well plates at a density of 2,000 cells/well. Following treatment with 1 , $0.1 \mu \mathrm{g} / \mathrm{ml}$ DOX for $1,2,3$ and 4 days; 2, 25, 50, 75 and $100 \mu \mathrm{g} / \mathrm{ml} \mathrm{SML}$ for 1, 2, 3 and 4 days; 3, DOX alone or SML plus DOX for 1, 2, 3 and 4 days, the cells were washed with PBS. RPMI-1640 medium (100 $\mu \mathrm{l})$ and $10 \mu \mathrm{l}$ cell counting kit- 8 solution (Beyotime Institute of Biotechnology) were added to each well for another $2 \mathrm{~h}$ at $37^{\circ} \mathrm{C}$. The optical density value was read at $450 \mathrm{~nm}$ using an ultraviolet spectrophotometer.

Cell apoptosis. The $2 \times 10^{5}$ cells were plated on a 6 -well plate. The SHG44/DOX cells were incubated at $37^{\circ} \mathrm{C}$ with $0.1 \mu \mathrm{g} / \mathrm{ml}$ DOX or $0.1 \mu \mathrm{g} / \mathrm{ml}$ DOX plus $50 \mu \mathrm{g} / \mathrm{ml} \mathrm{SML}$ for $96 \mathrm{~h}$, and the early apoptotic rate was analyzed by flow cytometry using the annexin V-phycoerythrin/7-aminoactinomycin D apoptosis reagent kit (Nanjing KeyGen Biotech Co., Ltd., Nanjing, China) according to a previous study (9).

DOX uptake. The SHG44/DOX cells were exposed to $0.1 \mu \mathrm{g} / \mathrm{ml}$ DOX or $0.1 \mu \mathrm{g} / \mathrm{ml}$ DOX plus $50 \mu \mathrm{g} / \mathrm{ml} \mathrm{SML}$ for $2 \mathrm{~h}$ at $37^{\circ} \mathrm{C}$. Subsequent to cell lysis and supernatant collection, the intracellular concentrations of DOX were tested using an ultraviolet spectrophotometer (absorbance, $490 \mathrm{~nm}$ ). In addition, the protein concentrations were analyzed to standardize the uptake of DOX.

Xenograft tumor model. The male nude mice ( $\mathrm{n}=9,4$ weeks old, weight $15 \mathrm{~g}$, maintained under specific pathogen free conditions at $20-26^{\circ} \mathrm{C}$, atmosphere $20-50 \mathrm{~Pa}, 12 \mathrm{~h}$ light/dark cycle, fed optionally) used in the present study were provided by the experimental Animal Center of Chongqing Medical University (Chongqing, China). All animal studies were approved by the Ethics Committee of Chongqing Medical University. The SHG44/DOX cells were resuspended in RPMI-1640 medium at a density of $2 \times 10^{6}$ cells per $80 \mu \mathrm{l}$ and injected subcutaneously. The $5 \mathrm{mg} / \mathrm{kg}$ DOX or $5 \mathrm{mg} / \mathrm{kg}$ DOX and $5 \mathrm{mg} / \mathrm{kg}$ SML was injected into tumor tissues every 7 days through the tail vein. Tumor volumes were recorded according to the formula described previously (10) at 7, 14, 21 and 28 days post-inoculation.

Immunohistochemistry (IHC). The mice were sacrificed at 28 days, and the xenograft tumors were dissected at $4 \mu \mathrm{m}$ and embedded in paraffin. IHC was performed according to previous methods (9) in order to evaluate the expression of Ki-67 (dilution, 1:100; cat. no. sc7844) and PCNA (dilution, 1:100; cat. no. sc25280) in the tumor tissues. Briefly, sections (4 $\mathrm{mm})$ were deparaffinized in xylene and rehydrated in ethanol with a descending concentration $(90,80,70,50 \%$ for $10 \mathrm{~min}$, respectively). Subsequently, these sections were treated with $3 \%$ hydrogen peroxide, the antigen was retrieved in citrate buffer, and nonspecific binding was blocked using $5 \%$ goat serum for $40 \mathrm{~min}$ at $37^{\circ} \mathrm{C}$. Following washing with $\mathrm{PBS}$, the sections were incubated overnight at $4^{\circ} \mathrm{C}$ with the Ki-67 (1:100) and PCNA (1:100), followed by incubation with the HRP goat anti-rabbit secondary antibody $(1: 2,000)$ at $37^{\circ} \mathrm{C}$ for $35 \mathrm{~min}$. Following staining with 3,3'-diaminobenzidine and counterstaining with hematoxylin (room temperature for $5 \mathrm{~min}$ ), the sections were observed using a light microscope (DM6000 B; Leica Microsystems GmbH, Wetzlar, Germany). The proliferation index (Ki-67 and PCNA index) was defined as the percentage of positive cells from five randomly selected fields under magnification, $x 400$. Negative controls (samples incubated with PBS instead of primary antibody) were processed along with the samples. There was no apparent immunoreactivity observed in negative controls.

Statistical analysis. One-way analysis of variance (SML toxicity, drug combination experiments in vitro and in vivo) and Tukey's post-hoc test or a paired t-test (western blot, RT-PCR, DOX toxicity) were performed using SPSS 20.0 (IBM SPSS, Armonk, NJ, USA). All data are presented as the mean \pm standard deviation. $\mathrm{P}<0.05$ was considered to indicate a statistically significant difference.

\section{Results}

Establishment and identification of SHG44/DOX cells. The glioma SHG44 cells were exposed to DOX with incremental concentrations, finally resulting in stable growth in $0.1 \mu \mathrm{g} / \mathrm{ml}$ DOX.RT-PCR analysis revealed that the mRNA levels of drug resistance genes (MDR1, MRP1 and LRP) in SHG44/DOX cells were significantly increased compared with SHG44 cells (Fig. 1A). Western blot analysis demonstrated that p-gp, MRP1 and LRP protein were also significantly elevated in SHG44/DOX cells compared with SHG44 cells (Fig. 1B). The $\mathrm{IC}_{50}$ values of DOX in SHG44 and SHG44/DOX cells were $1.64 \pm 0.27$ and $17.58 \pm 0.31 \mathrm{mg} / \mathrm{ml}$, respectively. Following 


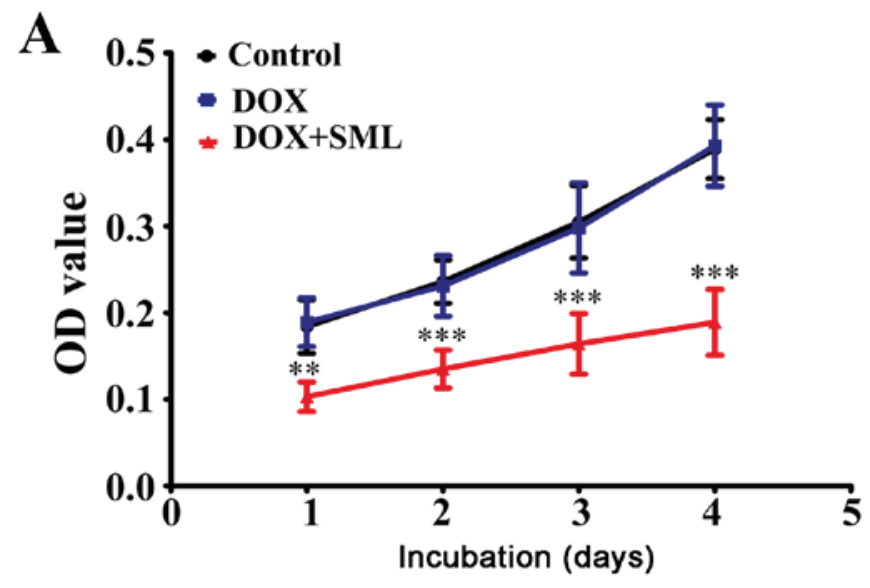

B

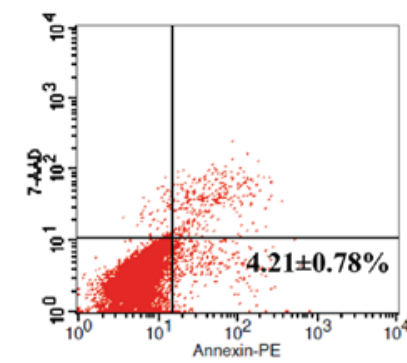

Control

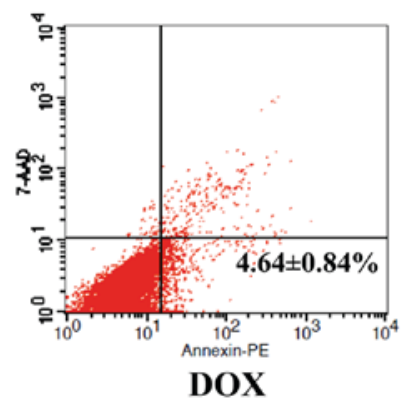

DOX

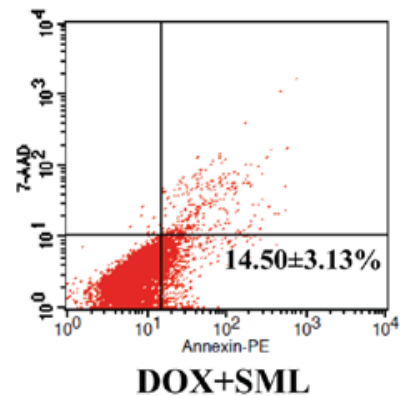

DOX+SML

Figure 3. SML restored the anticancer effects of DOX on SHG44/DOX cells in vitro. (A) Cell counting kit-8 was used to determine the growth of SHG44/DOX cells following incubation with DOX alone or SML plus DOX for $1,2,3$ and 4 days ( $\mathrm{n}=9 ;{ }^{* *} \mathrm{P}<0.01,{ }^{* * *} \mathrm{P}<0.001$ vs. control group). (B) The rates of cells undergoing early apoptosis were detected in the control, DOX alone and SML plus DOX groups using flow cytometry (n=5). SML, Salvia miltiorrhiza ligustrazine; DOX, doxorubicin; SHG44/DOX, DOX-resistant SHG44; OD, optical density; PE, phycoerythrin.

treatment with $0.1 \mu \mathrm{g} / \mathrm{ml}$ DOX for 1,2, 3 and 4 days, the viability of SHG44/DOX cells was higher compared with SHG44 cells (Fig. 1C). These results indicated that the SHG44/DOX cells successfully exhibited the DOX-resistant phenotype.

Cytotoxicity of SML in SHG44/DOX cells. In order to avoid the toxicity of SML, the non-toxic concentrations of this traditional Chinese medicine were selected. Following treatment with a concentration of $50 \mu \mathrm{g} / \mathrm{ml}$ or below for $1,2,3$ and 4 days, SML did not inhibit growth of SHG44/DOX cells. However, the traditional Chinese medicine was able to reduce proliferation of SHG44/DOX cells at a concentration of $75 \mu \mathrm{g} / \mathrm{ml}$ and above (Fig. 2). Therefore, $50 \mu \mathrm{g} / \mathrm{ml} \mathrm{SML} \mathrm{was}$ used as a non-toxic concentration for subsequent study.

SML inhibits DOX-resistance of SHG44/DOX cells. Although little cytotoxicity was observed in the $0.1 \mu \mathrm{g} / \mathrm{ml}$ DOX alone treatment group, $50 \mu \mathrm{g} / \mathrm{ml}$ SML plus $0.1 \mu \mathrm{g} / \mathrm{ml}$ DOX was able to suppress growth of SHG44/DOX cells after 1,2, 3 and 4 days (Fig. 3A). Flow cytometry demonstrated that the rates of early apoptosis were lower in the control and $0.1 \mu \mathrm{g} / \mathrm{ml} \mathrm{DOX}$ alone groups compared with the $50 \mu \mathrm{g} / \mathrm{ml} \mathrm{SML}$ plus $0.1 \mu \mathrm{g} / \mathrm{ml}$ DOX group after $96 \mathrm{~h}(\mathrm{P}<0.05$; Fig. 3B).

DOX-resistance of SHG44/DOX is attenuated by SML in vivo. Subcutaneous injections of SHG44/DOX cells were administered in nude mice to develop xenograft tumors. As shown in Fig. 4A, $5 \mathrm{mg} / \mathrm{kg}$ DOX was able to slightly inhibit SHG44/DOX growth in vivo compared with the control group after 21 days. However, the tumor suppression was stronger in the $5 \mathrm{mg} / \mathrm{kg}$ DOX plus $5 \mathrm{mg} / \mathrm{kg}$ SML group compared with the $5 \mathrm{mg} / \mathrm{kg}$ DOX alone group. Furthermore, the Ki-67 and PCNA proliferation indexes were significantly lower in the $5 \mathrm{mg} / \mathrm{kg}$ DOX plus $5 \mathrm{mg} / \mathrm{kg}$ SML group compared with the $5 \mathrm{mg} / \mathrm{kg}$ DOX alone group (Fig. 4B). The present data affirmed that SML reduced DOX-resistance in SHG44/DOX cells and improved the antitumor function of DOX.

SML downregulates multidrug resistance genes and facilitates DOX uptake in SHG44/DOX cells. Following treatment with $0.1 \mu \mathrm{g} / \mathrm{ml}$ DOX for $2 \mathrm{~h}$, the intracellular concentration of DOX was determined using spectrophotometry. It was demonstrated that concentration of DOX was higher in SHG44 cells compared with SHG44/DOX cells (Fig. 5A). Notably, treatment with $50 \mu \mathrm{g} / \mathrm{ml} \mathrm{SML}$ significantly increased the intracellular concentrations of DOX in SHG44/DOX cells (Fig. 5A). RT-qPCR and western blot analysis demonstrated that the mRNA and protein levels of MDR1, MRP1 and LRP were significantly downregulated by $50 \mu \mathrm{g} / \mathrm{ml} \mathrm{SML} \mathrm{in}$ SHG44/DOX cells (Fig. 5B and C).

\section{Discussion}

SML improves circulatory disturbance by vasodilation, and is also able to reduce blood viscosity by promoting 


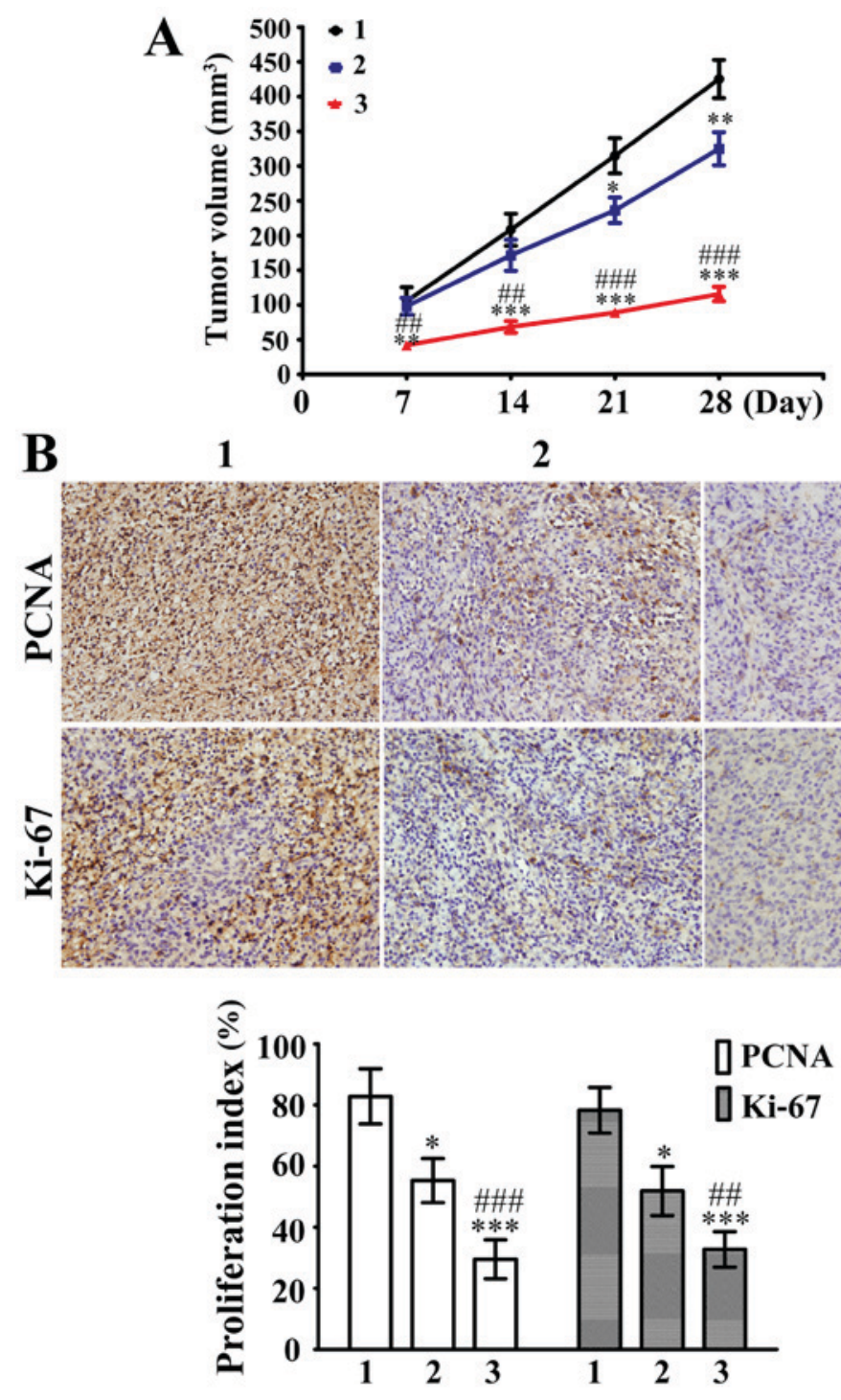

Figure 4. SML inhibited DOX-resistance in DOX-resistant SHG44 cells in vivo. (A) The xenograft tumors were divided into 1, control; 2, DOX alone; and 3 , DOX plus SML groups. The tumor volumes were calculated at day 7, 14, 21 and $28(n=3)$. (B) Immunohistochemical analysis was performed to analyze the percentage of cells positive for PCNA and Ki-67 in these tumor samples 28 days post-inoculation. Magnification, $\mathrm{x} 400 .{ }^{*} \mathrm{P}<0.05,{ }^{* * *} \mathrm{P}<0.01,{ }^{* * * *} \mathrm{P}<0.001$ vs. control group; ${ }^{\# \#} \mathrm{P}<0.01,{ }^{\# \#} \mathrm{P}<0.001$ vs. DOX alone group. SML, Salvia miltiorrhiza ligustrazine; DOX, doxorubicin; PCNA, proliferating cell nuclear antigen.

fibrinolysis $(11,12)$. Additionally, ligustrazine is able to increase the surface charge of erythrocytes and platelet to inhibit blood viscosity (13). Therefore, SML has played an important role in the treatment of cardiovascular and cerebrovascular diseases in China, having been widely used for the treatment of a number of conditions, including cerebral infarction, coronary disease, diabetic nephropathy and pulmonary heart disease (14-17). In previous years, with continuous research and clinical observation of the pharmacological effects of SML, SML has been indicated to have anticancer characteristics (18). Lin et al (19) demonstrated that SML was able to inhibit glucose metabolism of gastric cancer cells, prevent proliferation and promote apoptosis of cancer cells by increasing levels of p53 mRNA. This contributed to the inactivation of AKT signaling pathways and cell arrest in the G2/M phase. Gong et al (20) reported that SML blocked the growth of prostate cancer by inhibiting tumor angiogenesis in mice. Wang et al (21) confirmed that ligustrazine affected the translocation of nuclear factor- $\mathrm{\kappa B}$ p 65 from the nucleus to cytoplasm, and subsequently was able to alter its transcriptional activity and the expression of target genes. This led to the reduction in growth of osteosarcoma cells in vitro and in vivo. In addition, a previous study revealed that ligustrazine suppressed cyclooxygenase 2 and reduced the ability of lung cancer cells to migrate and invade (22). These data suggested that SML may be a potent agent for clinical therapy of tumors.

Multidrug resistance was indicated to be an important factor that hindered the complete elimination of glioma cells during radiotherapy and chemotherapy, resulting in poor prognosis for patients with glioma (23). The mechanisms of resistance may be associated with the expression of ATP-binding cassette transporter (ABC transporter) on the glioma cell membranes, which represents a group of transporters, including 49 genes and 7 different functional subfamilies (24). A number of studies have reported that the expression of LRP, MRP1 and p-gp in these subfamilies was upregulated in glioma cells $(4,25)$. These drug resistance genes caused failure in chemotherapy treatment of glioma by a number of mechanisms, including efflux of drugs, increasing 

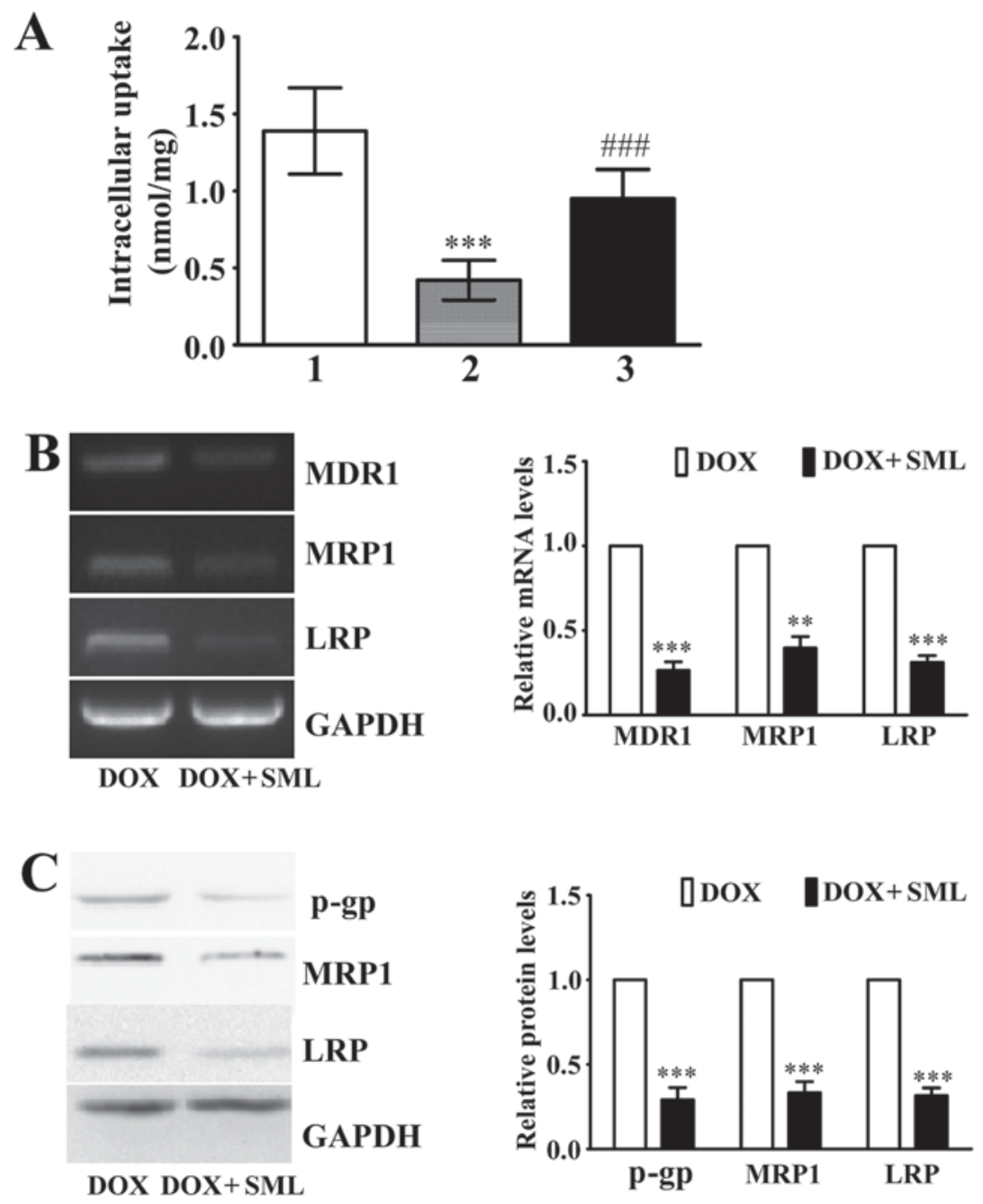

Figure 5. Effects of multidrug resistance genes and DOX uptake in SHG44/DOX cells. (A) Following exposure to DOX for $2 \mathrm{~h}$, the spectrophotometer was used to investigate intracellular concentrations of DOX in SHG44, SHG44/DOX and SHG44/DOX cells that were treated simultaneously with SML ${ }^{* * * *} \mathrm{P}<0.001$ vs. DOX treated-SHG44 cells; ${ }^{\# \# \#} \mathrm{P}<0.001$ vs. SHG44/DOX incubated with DOX alone; $\mathrm{n}=5.1$, SHG44 cells treated with DOX alone; 2 , SHG44/DOX cells treated with DOX alone; 3, SHG44/DOX cells treated with DOX + SML. (B) Reverse transcription-polymerase chain reaction analysis to observe the effects of SML treatment on the levels of MDR1, MRP1 and LRP mRNA in SHG44/DOX cells. ${ }^{* *} \mathrm{P}<0.01,{ }^{* * *} \mathrm{P}<0.001$ vs. the DOX alone group; $\mathrm{n}=5$. (C) Western blot analysis to analyze the effects of SML treatment on the protein expression of p-gp, MRP1 and LRP in SHG44/DOX cells. ${ }^{* * *} \mathrm{P}<0.001 \mathrm{vs.} \mathrm{DOX}$ alone group; $(\mathrm{n}=5)$. SML, Salvia miltiorrhiza ligustrazine; DOX, doxorubicin; MDR1, multidrug resistance 1; MRP1, multidrug resistance-associated protein 1; LRP, lung resistance protein; p-gp, phosphorylated glycoprotein; SHG44/DOX, DOX-resistant SHG44.

intracellular alkaline, changing membrane lipid structure and intracellular ionic environment, and accelerating glutathione to form the GST-X pump (26,27). These data suggested that downregulation of these genes may be helpful for increasing the intracellular concentrations of chemotherapy drugs and inducing antitumor effects. Therefore, these genes may be potential targets for gene therapy in glioma.

To date, a number of studies have shown that SML inhibits the proliferation of glioma $(28,29)$. However, to the best of our knowledge, there was no study reporting whether SML reduced resistance to chemotherapy. In the present study, a DOX-resistant glioma SHG44/DOX cell line was established, and it was revealed that the SHG44/DOX cells were more sensitive to DOX following exposure to SML. The combination of SML with DOX reversed the drug resistance of SHG44/DOX by inhibiting proliferation and tumor growth, and promoting early apoptosis. In studies on breast and colon cancer, the potential mechanisms of reversal of chemotherapeutic resistance were associated with inhibiting the levels of $\mathrm{ABC}$ transporter in tumor cells $(30,31)$. In the present study, it was also demonstrated that SML increased the intercellular concentration of DOX by reducing the expression of drug resistance genes in SHG44/DOX cells, which increased the antitumor ability of DOX.

In summary, the present study provides the experimental basis for clinical application of SML to reverse glioma chemotherapy resistance and improve the efficacy of chemotherapy drugs on the disease. The antitumor effects of SML may be a novel strategy for brain tumor chemotherapy, which may enable the development of Chinese medicine in cancer therapy.

\section{Acknowledgements}

The present study was supported by the Scientific Research Project of Health Bureau, Chongqing Municipal Health 
Bureau Traditional Chinese Medicine Scientific Research Project (grant no. ZY201402092).

\section{References}

1. Sturm D, Bender S, Jones DT, Lichter P, Grill J, Becher O, Hawkins C, Majewski J, Jones C, Costello JF, et al: Paediatric and adult glioblastoma: Multiform (epi)genomic culprits emerge. Nat Rev Cancer 14: 92-107, 2014.

2. Auffinger B, Spencer D, Pytel P, Ahmed AU and Lesniak MS: The role of glioma stem cells in chemotherapy resistance and glioblastoma multiforme recurrence. Expert Rev Neurother 15: 741-752, 2015.

3. Van Meir EG, Hadjipanayis CG, Norden AD, Shu HK, Wen PY and Olson JJ: Exciting new advances in neuro-oncology: The avenue to a cure for malignant glioma. CA Cancer J Clin 60 166-193, 2010

4. de Faria GP, de Oliveira JA, de Oliveira JG, Romano Sde O, Neto VM and Maia RC: Differences in the expression pattern of P-glycoprotein and MRP1 in low-grade and high-grade gliomas. Cancer Invest 26: 883-889, 2008.

5. Jin Y, Bin ZQ, Qiang H, Liang C, Hua C, Jun D, Dong WA and Qing L: ABCG2 is related with the grade of glioma and resistance to mitoxantone, a chemotherapeutic drug for glioma. J Cancer Res Clin Oncol 135: 1369-1376, 2009.

6. Bleau AM, Huse JT and Holland EC: The ABCG2 resistance network of glioblastoma. Cell Cycle 8: 2936-2944, 2009.

7. Zhang R, Saito R, Shibahara I, Sugiyama S, Kanamori M, Sonoda $\mathrm{Y}$ and Tominaga T: Temozolomide reverses doxorubicin resistance by inhibiting P-glycoprotein in malignant glioma cells. J Neurooncol 126: 235-242, 2016.

8. Singh MS and Lamprecht A: P-glycoprotein inhibition of drug resistant cell lines by nanoparticles. Drug Dev Ind Pharm 42: 325-331, 2016

9. Huang N, Chen S, Deng J, Huang Q, Liao P, Wang F and Cheng Y: Over-expression of S100A9 in human glioma and in-vitro inhibition by aspirin. Eur J Cancer Prev 22: 585-595, 2013.

10. Chen S, Zhao H, Deng J, Liao P, Xu Z and Cheng Y: Comparative proteomics of glioma stem cells and differentiated tumor cells identifies S100A9 as a potential therapeutic target. J Cell Biochem 114: 2795-2808, 2013.

11. Deng Y, Ng ES, Kwan YW, Lau CB, Cheung DW, Koon JC, Zhang Z, Zuo Z, Leung PC, Fung KP and Lam FF: Cerebral vasodilator properties of Danshen and Gegen: A study of their combined efficacy and mechanisms of actions. Phytomedicine 21: 391-399, 2014

12. Van Poppel PC, Breedveld P, Abbink EJ, Roelofs H, van Heerde W, Smits P, Lin W, Tan AH, Russel FG, Donders R, et al: Salvia miltiorrhiza root water-extract (Danshen) has no beneficial effect on cardiovascular risk factors. A Randomized Double-Blind Cross-Over Trial. PLoS One 10: e0128695, 2015.

13. Cai X, Chen Z, Pan X, Xia L, Chen P, Yang Y, Hu H, Zhang J, $\mathrm{Li} \mathrm{K}, \mathrm{Ge} \mathrm{J}$, et al: Inhibition of angiogenesis, fibrosis and thrombosis by tetramethylpyrazine: Mechanisms contributing to the SDF-1/CXCR4 axis. PLoS One 9: e88176, 2014.

14. Lin TH and Hsieh CL: Pharmacological effects of Salvia miltiorrhiza (Danshen) on cerebral infarction. Chin Med 5: 22, 2010.

15. Luo J, Song W, Yang G, Xu H and Chen K: Compound danshen (Salvia miltiorrhiza) dripping pill for coronary heart disease: An overview of systematic reviews. Am J Chin Med 43: 25-43, 2015.

16. Lee SH, Kim YS, Lee SJ and Lee BC: The protective effect of Salvia miltiorrhiza in an animal model of early experimentally induced diabetic nephropathy. J Ethnopharmacol 137: 1409-1414, 2011.
17. Liu Y, Huang Y, Zhao C, Qin X, Zhu Q, Chen S and Qu J: Salvia miltiorrhiza injection on pulmonary heart disease: A systematic review and meta-analysis. Am J Chin Med 42: 1315-1331, 2014

18. Chen X, Guo J, Bao J, Lu J and Wang Y: The anticancer properties of Salvia miltiorrhiza Bunge (Danshen): A systematic review. Med Res Rev 34: 768-794, 2014.

19. Lin LL, Hsia CR, Hsu CL, Huang HC and Juan HF: Integrating transcriptomics and proteomics to show that tanshinone IIA suppresses cell growth by blocking glucose metabolism in gastric cancer cells. BMC Genomics 16: 41, 2015.

20. Gong Y, Li Y, Lu Y, Li L, Abdolmaleky H, Blackburn GL and Zhou JR: Bioactive tanshinones in Salvia miltiorrhiza inhibit the growth of prostate cancer cells in vitro and in mice. Int J Cancer 129: 1042-1052, 2011 .

21. Wang Y, Fu Q and Zhao W: Tetramethylpyrazine inhibits osteosarcoma cell proliferation via downregulation of NF- $\mathrm{B}$ in vitro and in vivo. Mol Med Rep 8: 984-988, 2013.

22. Zheng CY, Xiao W, Zhu MX, Pan XJ, Yang ZH and Zhou SY: Inhibition of cyclooxygenase-2 by tetramethylpyrazine and its effects on A549 cell invasion and metastasis. Int J Oncol 40: 2029-2037, 2012

23. Tivnan A, Zakaria Z, O'Leary C, Kögel D, Pokorny JL, Sarkaria JN and Prehn JH: Inhibition of multidrug resistance protein 1 (MRP1) improves chemotherapy drug response in primary and recurrent glioblastoma multiforme. Front Neurosci 9: 218, 2015.

24. de Jonge-Peeters SD, Kuipers F, de Vries EG and Vellenga E: $\mathrm{ABC}$ transporter expression in hematopoietic stem cells and the role in AML drug resistance. Crit Rev Oncol Hematol 62: 214-226, 2007.

25. Andersson U, Malmer B, Bergenheim AT, Brännström T and Henriksson R: Heterogeneity in the expression of markers for drug resistance in brain tumors. Clin Neuropathol 23: 21-27, 2004.

26. Agarwal S, Sane R, Gallardo JL, Ohlfest JR and Elmquist WF: Distribution of gefitinib to the brain is limited by $\mathrm{P}$-glycoprotein (ABCB1) and breast cancer resistance protein (ABCG2)-mediated active efflux. J Pharmacol Exp Ther 334: 147-155, 2010.

27. Deeley RG and Cole SP: Substrate recognition and transport by multidrug resistance protein 1 (ABCC1). FEBS Lett 580: 1103-1111, 2006.

28. Yu K, Chen Z, Pan X, Yang Y, Tian S, Zhang J, Ge J, Ambati B and Zhuang J: Tetramethylpyrazine-mediated suppression of C6 gliomas involves inhibition of chemokine receptor CXCR4 expression. Oncol Rep 28: 955-960, 2012.

29. Lu L, Li C, Li D, Wang Y, Zhou C, Shao W, Peng J, You Y, Zhang $\mathrm{X}$ and Shen $\mathrm{X}$ : Cryptotanshinone inhibits human glioma cell proliferation by suppressing STAT3 signaling. Mol Cell Biochem 381: 273-282, 2013

30. Cai J, Chen S, Zhang W, Zheng X, Hu S, Pang C, Lu J, Xing J and Dong Y: Salvianolic acid A reverses paclitaxel resistance in human breast cancer MCF-7 cells via targeting the expression of transgelin 2 and attenuating PI3K/Akt pathway. Phytomedicine 21: 1725-1732, 2014.

31. Hu T, To KK, Wang L, Zhang L, Lu L, Shen J, Chan RL, Li M, Yeung JH and Cho CH: Reversal of P-glycoprotein (P-gp) mediated multidrug resistance in colon cancer cells by cryptotanshinone and dihydrotanshinone of Salvia miltiorrhiza. Phytomedicine 21: 1264-1272, 2014 